\title{
Qualidade físico-química de ameixas ‘Letícia’ produzidas sobre porta- enxertos clonais e em plantas autoenraizadas, no meio-oeste de Santa Catarina
}

\author{
Physicochemical quality of 'Letícia' plums produced on clonal rootstocks and own-rooted trees, in \\ the Midwest of Santa Catarina state, Brazil
}

\author{
Angelica Bender ${ }^{1^{*}}$ (ORCID 0000-0002-1141-6090), André Luiz Kulkamp de Souza ${ }^{2}$ (ORCID 0000-0003-4889-6291), Marco \\ Antônio Dalbó2 (ORCID 0000-0002-9203-2362), Newton Alex Mayer³ (ORCID 0000-0001-6689-8202)
}

\author{
1Universidade Federal de Pelotas, Pelotas, RS, Brasil. *Autor para correspondência: bender.angelica.fruti@gmail.com \\ ${ }^{2}$ Empresa de Pesquisa Agropecuária e Extensão Rural de Santa Catarina, Videira, SC, Brasil. \\ ${ }^{3}$ Embrapa Clima Temperado, Pelotas, RS, Brasil.
}

Submissão: 14/07/2021 / Aceite: 02/09/2021

\begin{abstract}
RESUMO
Objetivou-se com esse trabalho avaliar os efeitos de porta-enxertos clonais e de plantas autoenraizadas na qualidade físico-química de ameixas 'Letícia', no meio-oeste de Santa Catarina-SC. Foram avaliados frutos da cv. Letícia produzidos nos ciclos produtivos de 2018, 2019 e 2020, provenientes de pomar experimental da Estação Experimental da Epagri em Videira-SC. As plantas foram enxertadas sobre 19 diferentes acessos (cultivares, híbridos interespecíficos e seleções) utilizados como porta-enxertos clonais, além da cv. Letícia autoenraizada (sem porta-enxerto). Avaliou-se acidez total, teor de sólidos solúveis, ratio, $\mathrm{pH}$, firmeza de polpa e cor da epiderme dos frutos. Os valores de $\mathrm{pH}$ oscilaram de 2,98 para o porta-enxerto 'Barrier' (2018) a 3,68 para plantas sobre 'Santa Rosa' (2020). 'Santa Rosa' como porta-enxerto destacou-se pelo maior ratio $(19,46)$ na safra 2020, seguido pelo 'Flordaguard em 2018 $(14,92)$. Os maiores valores de firmeza foram obtidos para GxN9 em 2018 e Nemared em 2020, e os menores por 'Santa Rosa' em 2019 e 2020. A resposta dos porta-enxertos não se repetiu ao longo das safras avaliadas, demonstrando que o fator safra teve maior influência sobre a qualidade dos frutos, com exceção de 'Santa Rosa'. Os porta-enxertos Rigitano, Clone 15 (Prunus mume), Nemared e I-67-52-4 ( $P$. persica) apresentaram incompatibilidade com a cultivar-copa Letícia. Plantas autoenraizadas de 'Letícia' produzem frutos com características físico-químicas semelhantes aos produzidos em plantas enxertadas nos porta-enxertos testados, tornando-se uma opção tecnicamente interessante de cultivo sem o uso de porta-enxertos.
\end{abstract}

PALAVRAS-CHAVE: ameixeira, Prunus salicina, sólidos solúveis, maturação.

\section{ABSTRACT}

The objective of this work was to evaluate the effects of clonal rootstocks and self-rooted plants on the physicochemical quality of 'Letícia' plums in the mid-west of Santa Catarina. The evaluated fruits were from the 2018 to $2020 \mathrm{crops}$, from an experimental orchard of cv. Letícia, whose plants were grafted onto 19 different accessions (cultivars, interspecific hybrids, and selections) used as clonal rootstocks, in addition to own-rooted Letícia, at the Epagri Experimental Station in Videira-SC. Here, we evaluated total acidity, soluble solids content, ratio, $\mathrm{pH}$, flesh firmness, and epidermis color of the fruits. The $\mathrm{pH}$ values ranged from 2.98 for the 'Barrier' rootstock (2018) to 3.68 for plants on 'Santa Rosa' (2020). 'Santa Rosa' as rootstock stood out for the highest ratio (19.46) in the 2020 harvest, followed by 'Flordaguard in 2018 (14.92). The highest firmness values were obtained for GxN9 in 2018 and Nemared in 2020, and the lowest for 'Santa Rosa' in 2019 and 2020. The performance of the rootstocks was not repeated throughout the evaluated crops, demonstrating that the yield factor had a greater influence on fruit quality, except for 'Santa Rosa'. The fruits of plants grafted onto 'Santa Rosa' showed more advanced maturation at harvest. 'Letícia' plums produced on 'Santa Rosa' presented precocity of maturation in relation to the other tested clonal rootstocks. The rootstocks Rigitano, Clone 15 (Prunus mume), Nemared and I-67-52-4 (P. persica) showed incompatibility with the 'Letícia' canopy cultivar. Own-rooted 'Leticia' plants produce fruits with physicochemical characteristics similar to those produced on plants grafted on the tested rootstocks, indicating that the own-root cultivation is a technically interesting option for this cultivar. 
KEYWORDS: plum tree, Prunus salicina, soluble solids, maturation.

\section{INTRODUÇÃO}

A ameixeira possui dezenas de espécies e mais de 6.000 cultivares originadas na Europa, Ásia e América. Apesar dessa grande diversidade, somente duas espécies apresentam importância econômica em nível mundial: a ameixeira japonesa (Prunus salicina e seus híbridos) e a europeia ( $P$. domestica). No Brasil predomina o cultivo da ameixeira japonesa e seus híbridos, cujos frutos destinam-se principalmente ao consumo in natura. Uma das cultivares de ameixeira japonesa mais plantadas em nível nacional é a cultivar Letícia (EIDAM et al. 2012, FIORAVANÇO et al. 2015). As ameixeiras japonesas, juntamente com o pessegueiro e a nectarineira, são as frutíferas de caroço de importância comercial no Brasil (MAYER et al. 2017, MAYER et al. 2018).

As espécies de frutíferas de caroço são predominantemente propagadas por enxertia em portaenxertos com características de interesse (JIMENES et al. 2020). No sul do Brasil, as cultivares Aldrighi e Capdeboscq, que eram muito cultivadas até a década de 1980 para o processamento dos frutos, também eram bastante utilizadas para produção de porta-enxertos devido à facilidade de obtenção de sementes, razoável porcentagem de germinação e também à boa compatibilidade com praticamente todos as cultivares de pessegueiro, nectarineira e ameixeira (FACHINELLO et al. 2000, OLDONI et al. 2019). DONADIO et al. (2019) descrevem algumas características importantes para os porta-enxertos, como por exemplo, estes devem ser de fácil propagação por sementes ou estacas, compatíveis com as cultivares copa e que apresentem sistema radicular que suporte o dossel, para uma boa produção.

As mudas de ameixeira, no Brasil, são tradicionalmente produzidas sobre porta-enxertos de pessegueiro, sendo o 'Okinawa' o porta-enxerto mais utilizado no Sudeste, e o 'A9', 'Capdeboscq' ou misturas de caroços de diversas cultivares tipo indústria, os mais utilizados na região Sul (FACHINELLO et al. 2020, MAYER et al. 2018). Porém, se o porta-enxerto não foi desenvolvido ou selecionado em função de vantagens agronômicas como sistema radicular, não há razão para a adoção de uma combinação interespecífica de enxertia (LORETI 2008, OLDONI et al. 2019). Como as ameixeiras são mais tolerantes ao encharcamento de solo (GUERRA et al. 1992), se propagam facilmente por estaquia e não apresentam incompatibilidade de enxertia com as cultivares copa de ameixeira, o uso de cultivares da mesma espécie ('Santa Rosa' e 'Genovesa'), das cultivares de porta-enxerto 'Mirabolano 29C' e 'Marianna 2624', ou mesmo plantas autoenraizadas (sem porta-enxerto) da própria cultivar copa podem ser alternativas mais interessantes, em relação ao uso de sementes de pessegueiro não selecionados para a função portaenxerto (MAYER et al. 2017, MAYER et al. 2018). No entanto, a eficiência técnica destas opções no campo ainda precisa ser comprovada.

O conhecimento da interação entre o porta-enxerto e a cultivar copa é de fundamental importância na tomada de decisão por técnicos e fruticultores, para a correta definição das mudas a serem adquiridas. Além de influenciar as características vegetativas da cultivar copa, o porta-enxerto também pode promover alterações na qualidade dos frutos e na produtividade (SZYMAJDA et al. 2019, OLIVEIRA et al. 2020, SANTANA et al. 2020).

Trabalhos tem sido realizados para identificação de quais os porta-enxertos são mais adequados para as diferentes condições edafoclimáticas brasileiras onde é possível cultivar as frutíferas de caroço. Informações de como diferentes porta-enxertos podem afetar as características de firmeza de polpa, sólidos solúveis (SS), acidez total (AT) e ratio (SS/AT) dos frutos são fundamentais para subsidiar recomendações a nível de microrregião. Valores de firmeza de polpa inferiores a 5,00 $\mathrm{N}$ indicam um elevado grau de maturação dos frutos, sendo valores superiores a 10,00 N necessários para frutos que serão transportados (YANG et al. 2012, BAUCHROWITZ 2018). CHAGAS (2008) descreve que o teor de sólidos solúveis para diferentes cultivares de ameixas no momento da colheita deve ser compreendido entre 9 e $13{ }^{\circ}$ Brix. MORAIS et al. (2017) consideraram que o teor de $10^{\circ}$ Brix é o mínimo aceito pelos consumidores. Quanto a acidez, CHAGAS (2008) afirma que ameixas podem apresentar de 0,5 a 3,0\% de ácidos orgânicos. QUEIROZ (2014) explica que o ratio é usualmente utilizada como indicador de maturação, sendo que, frutos com acidez total menor que $0,6 \%$ e sólidos solúveis de 10 a $12 \%$ são considerados doces, no entanto, quando a acidez total é superior a $1 \%$ é necessário um teor de sólidos solúveis acima de $15^{\circ}$ Brix para que o consumidor sinta o sabor doce do fruto. BAUCHROWITZ et al. (2019) descrevem que um valor de ratio de aproximadamente 10 é aceitável para o mercado consumidor. ARGENTA et al. (2003) afirmam que o valor mínimo para o ratio de frutas é de 11,4 .

Objetivou-se com este trabalho avaliar a qualidade físico-química dos frutos da ameixeira 'Letícia' 
produzida sobre diferentes porta-enxertos clonais e plantas auto enraizadas, no meio oeste de Santa Catarina.

\section{MATERIAL E MÉTODOS}

Para a avaliação da cv. Letícia sobre diferentes porta-enxertos foram utilizados frutos produzidos em pomar experimental da Epagri - Empresa de Pesquisa Agropecuária e Extensão Rural de Santa Catarina, Estação Experimental de Videira (Videira, SC/Brasil), localizada sob as coordenadas de latitude $27^{\circ} 02^{\prime} 27,59^{\prime \prime} \mathrm{S}$ e longitude $51^{\circ} 08^{\prime} 04,73^{\prime \prime} \mathrm{W}$, com altitude de 830 metros acima do nível do mar, durante as safras 2018, 2019 e 2020. O clima da região de acordo com KÖPPEN (2014) é classificado como mesotérmico úmido e verão ameno $(\mathrm{Cfb})$. As médias de precipitação, temperatura média e umidade relativa nos meses que englobam o período de amadurecimento e colheita (dezembro a março) das safras 2018 a 2020 estão listados na Tabela 1 (EPAGRI/CIRAM).

Tabela 1. Somatório da precipitação e média das temperaturas máxima, mínima e média durante os meses que englobam o período de maturação e colheitas de ameixas da cv. Letícia, na Região do Vale do Rio do Peixe, SC, nos ciclos 2017/18, 2018/19 e 2019/20.

Table 1. Sum of precipitation and average of maximum, minimum and average temperatures during the months that comprise the maturation and harvest of plums of cv. Letícia, in the region of Rio do Peixe Valley, SC, in the 2017/18, 2018/19 and 2019/20 cycles.

\begin{tabular}{lccccc}
\hline & \multicolumn{5}{c}{ Variáveis } \\
\cline { 2 - 6 } Meses & $\begin{array}{c}\text { Temp. Máxima } \\
\left({ }^{\circ} \mathrm{C}\right)\end{array}$ & $\begin{array}{c}\text { Temp. Mínima } \\
\left({ }^{\circ} \mathrm{C}\right)\end{array}$ & $\begin{array}{c}\text { Temp. Média } \\
\left({ }^{\circ} \mathrm{C}\right)\end{array}$ & $\begin{array}{c}\text { Precipitação } \\
(\mathrm{mm})\end{array}$ & $\begin{array}{c}\text { Precipitação } \\
\text { acumulada } \\
(\mathrm{mm})\end{array}$ \\
\hline Dez & 29,04 & 17,25 & $2017 / 18$ & \\
Jan & 27,99 & 17,53 & 21,55 & 139,80 & 525,20 \\
Fev & 27,17 & 15,44 & 20,53 & 70,40 & \\
Mar & 27,72 & 16,99 & 21,23 & 236,00 & \\
\hline \multicolumn{5}{c}{$2018 / 19$} \\
\hline Dez & 30,42 & 15,72 & 21,84 & 136,40 \\
Jan & 31,26 & 19,35 & 23,72 & 316,40 & \\
Fev & 27,84 & 17,38 & 21,36 & 173,40 & \\
Mar & 27,18 & 16,63 & 20,63 & 263,60 & \\
\hline \multicolumn{5}{c}{$2019 / 20$} \\
\hline Dez & 22,48 & 21,17 & 21,81 & \\
Jan & 22,96 & 21,69 & 22,30 & 206,20 & \\
Fev & 21,94 & 20,60 & 21,25 & 213,40 & \\
Mar & 21,73 & 20,20 & 20,96 & 48,40 & \\
\hline
\end{tabular}

O delineamento utilizado foi em blocos casualizados, com quatro repetições de uma planta para cada tratamento (porta-enxertos clonais e a testemunha auto enraizada). O pomar foi implantado em $2014 \mathrm{em}$ sistema de condução em Y, com duas pernadas transversais à linha de plantio, formando um túnel entre as fileiras. O espaçamento foi de 1,3 m entre plantas na linha por 5,0 m entre linhas, totalizando 1.538 plantas por hectare, em área sem irrigação. As adubações de correção e manutenção foram realizadas anualmente, mediante análises químicas de solo e foliar e interpretação segundo o Manual de Adubação e Calagem para os Estados do Rio Grande do Sul e Santa Catarina (SBCS/CQFS 2004).

Mudas da ameixeira cv. Letícia foram produzidas em embalagens plásticas com substrato comercial à base de casca de pínus (30\%) e turfa (70\%), entre 2012 e 2014. Como porta-enxertos, foram utilizados 19 acessos (cultivares, híbridos interespecíficos de domínio público e seleções) propagados por enraizamento de estacas herbáceas (Tabela 2), além da própria cultivar auto enraizada (testemunha, sem porta-enxerto). A seleção dos porta-enxertos se deu baseado em dados preliminares e uso de parte da variabilidade genética disponível, na "Coleção Porta-enxerto de Prunus", da Embrapa Clima Temperado (Pelotas,RS).

Foram amostrados 15 frutos de cada repetição oriundos de plantas do cv. Leticia enxertada sobre diferentes porta-enxertos (Tabela 2). A colheita ocorreu no mesmo dia para todos os tratamentos e o critério foi a maioria coloração e firmeza dos frutos. As variáveis analisadas foram acidez total, teor de sólidos solúveis, ratio, $\mathrm{pH}$, firmeza de polpa e cor da epiderme. Os valores de AT (g de ácido cítrico $100 \mathrm{~g}^{-1}$ ) foram 
obtidos através de uma amostra de $10 \mathrm{~mL}$ de suco dos frutos, previamente extraído de fatias transversais retiradas da região equatorial das ameixas e trituradas em uma centrífuga elétrica. Esta amostra foi diluída em $50 \mathrm{~mL}$ de água destilada e titulada com solução de hidróxido de sódio $0,1 \mathrm{~N}$ até pH 8,2. Os teores de sólidos solúveis (ํㅜrix) foram determinados em refratômetro digital de bancada com compensação automática de temperatura, utilizando-se do suco extraído conforme descrito para a acidez titulável. O pH foi avaliado em pHmetro de bancada. O ratio foi determinado pela relação do teor de sólidos solúveis e acidez titulável (SS/AT).

Tabela 2. Cultivares, híbridos interespecíficos e seleções de Prunus spp. testadas como porta-enxertos clonais para a ameixeira 'Letícia', na Região do Vale do Rio do Peixe, SC.

Table 2. Cultivars, interspecific hybrids, and selections of Prunus spp. evaluated as clonal rootstocks for 'Letícia' plum, in Rio do Peixe Valley, SC.

\begin{tabular}{|c|c|c|c|}
\hline Porta-enxerto & Espécie & Porta-enxerto & Espécie \\
\hline Barrier & P. pérsica $\times$ P. davidiana & I- $67-52-4$ & Prunus persica \\
\hline Cadaman & P. pérsica $\times$ P. davidiana & Tsukuba - 1 & Prunus persica \\
\hline$G \times N .9$ & P. pérsica $\times$ P. dulcis & Tsukuba - 2 & Prunus persica \\
\hline Capdeboscq & P. persica & Tsukuba - 3 & Prunus persica \\
\hline Mirabolano $29 \mathrm{C}$ & P. cerasifera & Okinawa & Prunus persica \\
\hline Genovesa & Prunussalicina & Nemared & Prunus persica \\
\hline Marianna 2624 & $\begin{array}{l}P \text {. cerasifera } \times P \text {. } \\
\text { munsoniana }\end{array}$ & Flordaguard & $\begin{array}{l}\text { Sexta geração descendente } \\
\text { de 'Chico } 11 \text { ' x } P \text {. davidiana }\end{array}$ \\
\hline Rigitano & Prunus mume & Ishtara & $\begin{array}{l}\text { (P. cerasifera } x \text { P. salicina) } x \\
(P . \text { cerasifera } x \text { P. pérsica) }\end{array}$ \\
\hline Clone 15 & Prunus mume & Santa Rosa & P. salicina \\
\hline México Fila 1 & Prunus persica & & \\
\hline
\end{tabular}

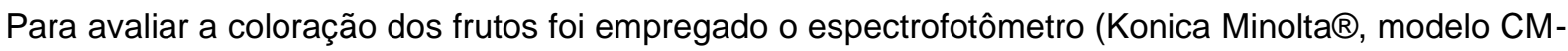
5), para determinação de $L^{*}, a^{*} e b^{*}$, sendo que $o L^{*}$ representa a luminosidade da amostra $\left(L^{*}=0\right.$ preto a 100 branco) e os valores de $a^{*}$ e $b^{*}$ foram empregados nos cálculos da intensidade (croma) e tonalidade da cor ( $\left.{ }^{\circ} \mathrm{HUE}\right)$, obtidas pelas seguintes fórmulas:

$$
\begin{gathered}
\mathrm{C}^{*}=\left[\left(\mathrm{a}^{*}\right) 2+\left(\mathrm{b}^{*}\right) 2\right] 1 / 4 \\
\mathrm{H}^{\circ}=\tan -1\left(\mathrm{~b}^{*} / \mathrm{a}^{*}\right) \text { quando } \mathrm{a}^{*}>0 \text { e } \mathrm{b}^{*} \geq 0 \\
\mathrm{H}^{\circ}=180+\tan -1\left(\mathrm{~b}^{*} / \mathrm{a}^{*}\right) \text { quando } \mathrm{a}^{*}<0
\end{gathered}
$$

As leituras foram realizadas na região equatorial dos frutos, nos lados menos e mais vermelhos, obtendo-se a média para cada fruto. A coloração dos frutos foi realizada somente nas safras 2019 e 2020. Em seguida, a firmeza de polpa $(\mathrm{N})$ foi determinada na região equatorial dos frutos, em dois lados opostos, após remoção de uma pequena porção da epiderme, com o auxílio de um penetrômetro manual equipado com ponteira de $7,9 \mathrm{~mm}$ de diâmetro.

Os dados obtidos foram analisados quanto à normalidade pelo teste de Shapiro Wilk; à homocedasticidade pelo teste de Hartley; e, à independência dos resíduos por análise gráfica. Posteriormente, os dados foram submetidos à análise de variância através do teste $F \quad(p \leq 0,05)$. Constatando-se significância estatística, os efeitos dos tipos de sucos foram comparados pelo teste de Scott Knott $(p \leq 0,05)$, empregando o aplicativo R (R Development Core Team 2018).

\section{RESULTADOS E DISCUSSÃO}

Os porta-enxertos Rigitano e Clone 15 ( $P$. mume) apresentaram incompatibilidade de enxertia com a ameixeira 'Letícia', o que ocasionou a morte de todas as plantas em até três meses após o plantio no campo, impossibilitando a realização de quaisquer avaliações em ambas combinações copa/porta-enxerto. $\mathrm{O}$ uso de clones de umezeiro ( $P$. mume) têm despertado interesse como porta-enxerto para pessegueiro devido à rusticidade, resistência a nematoides-de-galhas, incremento da massa dos frutos, adaptabilidade e diminuição do vigor da planta, desde que sejam utilizados acessos selecionados e propagados vegetativamente (MAYER et al. 2005 e 2008, MAYER \& PEREIRA 2006, PEREIRA et al. 2007, VIEITES et 
al. 2016). No entanto, ambos clones (Rigitano e Clone 15) ainda não haviam sido testados para ameixeira japonesa e o presente trabalho demonstrou que são inviáveis para a ameixeira 'Letícia'. As plantas enxertadas sobre 'Nemared' e I-67-52-4 apresentaram baixo desenvolvimento vegetativo, não havendo frutos suficientes para avaliação em nenhuma das safras.

Para a variável $\mathrm{pH}$ ocorreram diferenças significativas para os diferentes porta-enxertos, os valores oscilaram de 2,98 ('Barrier' em 2018) a 3,68 ('Santa Rosa' em 2020) (Tabela 3). De maneira geral, as ameixas da cv. Letícia apresentaram valores menores de pH na safra 2019 em relação as safras 2018 e 2020, com exceção do porta-enxerto 'Mariana 2624', que teve pH mais elevado em 2019 (Tabela 3). SAARELA et al. (2011) e SHARMA \& SHARMA (2016) explicam que é possível observar a existência de diferentes valores de $\mathrm{pH}$ na polpa dos frutos, isso ocorre porque mesmos os frutos produzidos em uma mesma planta possuem diferenças entre si. BAUCHROWITZ et al. (2019b) avaliaram o genótipo de ameixeira japonesa Byron 81-5850 no município de Ponta Grossa, PR nas safras de 2013 a 2015 e verificaram valores de $\mathrm{pH}$ de 3,00 a 3,12 semelhantes aos verificados para os frutos da cv. Letícia. Os autores declararam que estes valores determinam um $\mathrm{pH}$ ácido, porém, condizentes com a literatura, que descreve que esta é uma característica que ocorre em todas as cultivares, sejam elas de origem europeia ou asiática (MACHADO et al. 2013).

Quanto ao teor de sólidos solúveis (Tabela 3), ocorreu efeito significativo dos porta-enxertos, com exceção da safra 2019, que não ocorreu diferença significativa para porta-enxertos, e para o porta-enxerto Ishtara, que não diferiu entre as safras. A safra 2019 apresentou o menor teor de sólidos solúveis em comparação as safras 2018 e 2020 . Os menores valores da safra 2019 podem ser resultado das condições climáticas de maior precipitação durante a fase de maturação dos frutos como pode ser evidenciado na Tabela 1. BAUCHROWITZ et al. (2019) explicam que variações nos resultados durante os anos de avaliação, são decorrentes principalmente devido a fatores não controlados, como o clima. Em trabalho conduzido com pêssego 'Chimarrita' sobre diferentes porta-enxertos realizado por SCHMITZ et al. (2012), os autores verificaram que os porta-enxertos não induziram variações significativas nos dois anos de avaliações no teor de sólidos solúveis, no entanto, no ano que a precipitação foi abaixo da média, a concentração de sólidos solúveis foi superior, indicando que as condições ambientais foram mais efetivas na indução de diferenças no teor de sólidos solúveis do que propriamente o efeito de porta-enxerto.

Os valores de sólidos solúveis variaram de 10,17 ${ }^{\circ}$ Brix para Tsukuba-2 em 2019 a 15,64 ${ }^{\circ}$ Brix em 2020 para cv. Santa Rosa. SANTANA et al. (2020) avaliaram a cv. de pêssego BRS Libra sobre diferentes porta-enxertos e também verificaram valores de sólidos solúveis mais elevados quando utilizado a cv. Santa Rosa como porta-enxerto. MORAIS et al. (2017) afirmam que um teor de sólidos solúveis de $10^{\circ}$ Brix é o mínimo aceito pelos consumidores, valor atendido pelos frutos avaliados. A faixa de valores encontrados no presente estudo é maior que os valores verificados por BAUCHROWITZ et al. (2019b) que encontraram 12,15 a 12,37 ${ }^{\circ}$ Brix para o cv. Byron 81-5850 e CUQUEL et al. (2011), que estudando frutos da cv. Reubennel, verificaram variações entre 11,5 a $14{ }^{\circ}$ Brix. PIO et al. (2018) avaliaram sete cultivares de ameixas enxertadas sob porta-enxerto Okinawa produzidas em clima subtropical, e verificaram valores que variaram de $9,30^{\circ}$ Brix para a cv. Santa Rosa a 15,04 para cv. Grancoure. ANZANELLO \& MENIN (2018) avaliaram a cv. Letícia na safra 2015 produzida nas condições da Serra Gaúcha e verificaram um teor de sólidos solúveis médio de $12,90^{\circ}$ Brix.

Acidez titulável (Tabela 3) foi menor em 2018 independente do porta-enxerto, com exceção dos frutos produzidos sobre cv. Santa Rosa que apresentaram teor menor na safra 2020 (0,80 g/100g de ácido cítrico), sendo o menor valor de acidez verificado em todo o experimento. Os teores de acidez variaram de 0,80

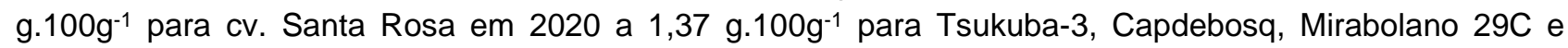
Nemared em 2019. VIEIRA et al. (2005) explicam que as variações nos valores de acidez titulável podem ser devido ao ponto de colheita dos frutos, o que pode justificar as diferenças observadas no presente trabalho, pois o critério de colheita dos frutos foi a coloração da epiderme. O destaque foi a cv. Santa Rosa quando utilizada como porta-enxerto, que apresentou uma menor acidez, podendo indicar que estes frutos apresentavam uma maturação mais avançada em relação aos demais porta-enxertos avaliados. Já as diferenças entre safras podem ser devidas as condições de clima distintas entres estas, bem como, o ponto de colheita pode ter sido distinto nas diferentes safras. A acidez de um fruto não é um parâmetro de descarte ou classificação, porque para ser analisado este fator é necessário a destruição do fruto, entretanto, os consumidores brasileiros preferem frutos com menores valores de acidez, sendo esta qualidade juntamente com os sólidos solúveis fonte de origem do ratio, e indicativos de qualidade dos frutos (BAUCHROWITZ et al. 2018). 
Tabela 3. pH; Sólidos solúveis (SS) e acidez titulável (AT) de frutos de ameixa do cultivar Letícia produzidos com diferentes porta-enxertos ou em plantas autoenraizadas, na Região do Vale do Rio do PeixeSC na Região do Vale do Rio do Peixe, SC.

Table 3. pH; Soluble solids (SS) and titratable acidity (TA) of plum fruits of the Letícia cultivar produced with different rootstocks or on own-rooted plants, in the Rio do Peixe Valley region, SC.

\begin{tabular}{|c|c|c|c|c|c|c|c|c|c|}
\hline \multicolumn{10}{|c|}{ Variáveis } \\
\hline \multirow{2}{*}{$\begin{array}{c}\text { Porta } \\
\text { enxertos }\end{array}$} & \multicolumn{3}{|c|}{$\mathrm{pH}$} & \multicolumn{3}{|c|}{ Sólidos Solúveis ( ${ }^{\circ}$ Brix) } & \multicolumn{3}{|c|}{$\begin{array}{c}\text { Acidez titulável } \\
\text { (\% de ácido cítrico) }\end{array}$} \\
\hline & 2018 & 2019 & 2020 & 2018 & 2019 & 2020 & 2018 & 2019 & 2020 \\
\hline Tsukuba -1 & $3,59 \mathrm{bA}$ & $3,01 \mathrm{bC}$ & $3,49 \mathrm{cB}$ & $12,25 \mathrm{bA}$ & $10,47 a B$ & $12,10 \mathrm{bA}$ & $1,24 \mathrm{aB}$ & $1,34 \mathrm{aA}$ & $1,38 a A$ \\
\hline Tsukuba - 2 & $3,65 \mathrm{aA}$ & $3,05 \mathrm{aC}$ & $3,55 \mathrm{bB}$ & 12,37 bA & $10,17 \mathrm{aB}$ & $12,20 \mathrm{bA}$ & $0,98 \mathrm{bC}$ & $1,32 \mathrm{aA}$ & $1,19 \mathrm{bB}$ \\
\hline Tsukuba - 3 & $3,47 \mathrm{dA}$ & $2,99 \mathrm{bB}$ & $3,49 \mathrm{cA}$ & $12,00 \mathrm{bA}$ & $10,32 \mathrm{aB}$ & $12,22 \mathrm{bA}$ & $1,17 \mathrm{aB}$ & $1,37 \mathrm{aA}$ & $1,30 \mathrm{aA}$ \\
\hline Autoenraizada & $3,52 \mathrm{cB}$ & $3,06 \mathrm{aC}$ & $3,58 \mathrm{bA}$ & $12,60 \mathrm{aA}$ & $10,90 \mathrm{aB}$ & $12,27 \mathrm{bA}$ & $0,94 \mathrm{bB}$ & $1,20 \mathrm{bA}$ & $1,14 \mathrm{bA}$ \\
\hline G. $\times$ N9 & $3,45 \mathrm{~dB}$ & $3,08 \mathrm{aC}$ & $3,53 \mathrm{bA}$ & $11,62 \mathrm{bB}$ & $10,70 \mathrm{aC}$ & $12,82 \mathrm{bA}$ & $1,10 \mathrm{aB}$ & $1,27 \mathrm{bA}$ & $1,24 \mathrm{aA}$ \\
\hline Cadaman & $3,44 d A$ & $3,06 \mathrm{aB}$ & $3,49 \mathrm{cA}$ & $13,60 \mathrm{aA}$ & $10,50 \mathrm{aB}$ & $11,60 \mathrm{bB}$ & $1,12 \mathrm{aB}$ & $1,23 \mathrm{bA}$ & $1,27 \mathrm{aA}$ \\
\hline Capdebosq & $3,47 \mathrm{dA}$ & $3,02 \mathrm{bB}$ & $3,53 \mathrm{bA}$ & $11,50 \mathrm{bA}$ & $10,20 \mathrm{aB}$ & $12,20 \mathrm{bA}$ & $1,12 \mathrm{aB}$ & $1,37 \mathrm{aA}$ & $1,20 \mathrm{bA}$ \\
\hline Mariana & $3,52 \mathrm{cA}$ & $3,09 \mathrm{aA}$ & $3,51 \mathrm{cB}$ & $12,37 \mathrm{bA}$ & $10,80 \mathrm{aB}$ & $12,40 \mathrm{bA}$ & $0,96 \mathrm{bB}$ & $1,17 \mathrm{bA}$ & $1,25 \mathrm{aA}$ \\
\hline Barrier & $3,50 \mathrm{cA}$ & $2,98 \mathrm{bB}$ & $3,51 \mathrm{cA}$ & 12,67 aA & $11,20 \mathrm{aB}$ & $13,05 \mathrm{bA}$ & $0,86 \mathrm{bB}$ & $1,24 \mathrm{bA}$ & $1,29 \mathrm{aA}$ \\
\hline México Fila 1 & $3,58 \mathrm{bA}$ & $3,00 \mathrm{bC}$ & $3,45 \mathrm{cB}$ & $12,62 \mathrm{aA}$ & $11,20 \mathrm{aB}$ & $12,07 \mathrm{bA}$ & $0,97 \mathrm{bB}$ & $1,27 \mathrm{bA}$ & $1,28 \mathrm{aA}$ \\
\hline Okinawa & $3,57 \mathrm{bA}$ & $3,02 \mathrm{bC}$ & $3,51 \mathrm{cB}$ & $12,07 \mathrm{bA}$ & $10,85 \mathrm{aB}$ & $12,12 \mathrm{bA}$ & $1,04 \mathrm{bB}$ & $1,29 \mathrm{bA}$ & $1,34 \mathrm{aA}$ \\
\hline Genovesa & $3,64 \mathrm{aA}$ & $3,05 \mathrm{aC}$ & $3,52 \mathrm{cB}$ & $12,52 \mathrm{aA}$ & $10,42 \mathrm{aB}$ & $12,90 \mathrm{bA}$ & $0,98 \mathrm{bB}$ & $1,26 \mathrm{bA}$ & $1,26 \mathrm{aA}$ \\
\hline Mirabolano & $3,64 \mathrm{aA}$ & $3,00 \mathrm{bC}$ & $3,52 \mathrm{cB}$ & $13,02 \mathrm{aA}$ & $10,75 \mathrm{aB}$ & $12,50 \mathrm{bA}$ & $0,98 \mathrm{bc}$ & $1,37 \mathrm{aA}$ & $1,21 \mathrm{bB}$ \\
\hline Santa Rosa & $3,54 \mathrm{cB}$ & $3,04 \mathrm{bC}$ & $3,68 \mathrm{aA}$ & $13,30 \mathrm{aB}$ & $10,60 \mathrm{aC}$ & $15,64 \mathrm{aA}$ & $0,97 \mathrm{bB}$ & $1,11 \mathrm{bA}$ & $0,80 \mathrm{cC}$ \\
\hline Ishtara & $3,65 \mathrm{aA}$ & $3,09 \mathrm{aC}$ & $3,54 \mathrm{bB}$ & $12,30 \mathrm{bNS}$ & $11,35 \mathrm{~A}$ & $12,27 \mathrm{bA}$ & $0,96 \mathrm{bB}$ & $1,21 \mathrm{bA}$ & $1,26 \mathrm{aA}$ \\
\hline Flordaguard & $3,60 \mathrm{aA}$ & $3,05 \mathrm{aC}$ & $3,51 \mathrm{cB}$ & $13,25 \mathrm{aA}$ & $10,95 \mathrm{aB}$ & $11,80 \mathrm{bB}$ & $0,89 \mathrm{bB}$ & $1,27 \mathrm{bA}$ & $1,29 \mathrm{aA}$ \\
\hline Nemared & $3,47 \mathrm{~dB}$ & $3,02 \mathrm{bC}$ & $3,56 \mathrm{bA}$ & $11,50 \mathrm{bA}$ & $10,20 \mathrm{aB}$ & $11,67 \mathrm{bA}$ & $1,12 \mathrm{aB}$ & $1,37 \mathrm{aA}$ & $1,28 \mathrm{aA}$ \\
\hline CV (\%) & & 1,32 & & & 5,29 & & & 6,86 & \\
\hline
\end{tabular}

Mesma letra minúscula na coluna não apresenta diferença significativa para porta enxerto dentro de safra. Mesma letra maiúscula na linha não apresenta diferença significativa para safra dentro de porta enxerto.

Os menores valores para ratio (Tabela 4) foram verificados na safra 2019 para todos porta-enxertos, devido ao menor teor de sólidos solúveis e maior acidez titulável dos frutos neste mesmo período. Os frutos da cv. Letícia quando produzidos sobre os porta-enxertos Capdebosc e Nemared apresentaram os menores valores para ratio de 7,45, na safra 2019. Os maiores valores de ratio foram obtidos quando os frutos foram produzidos sobre a cv. Santa Rosa na safra 2020 (19,46), seguido por Flordaguard em 2018 (14,92). (BAUCHROWITZ et al. 2019b) explicam que valores próximos de 10 para ratio são aceitáveis para o mercado consumidor, principalmente para frutos destinados a indústria, estes autores encontraram valores de 9,95 a 10,43. DÍAZ-MULA et al. (2009) relatam que os valores verificados na literatura variam de 6,68 a 10,56. CRISOSTO et al. (2007), (MINAS et al. 2013), BAUCHROWITZ et al. (2019a) concluíram que o maior ratio resulta em maior aceitação pelo consumidor, sendo que a alta acidez interfere negativamente, diminuindo o ratio.

A firmeza dos frutos apresentou diferenças significativas para porta-enxertos em todas as safras avaliadas, sendo os maiores valores obtidos para GxN9 em $2018(8,18 \mathrm{~N})$, seguido por Nemared em 2020 $(8,00 \mathrm{~N})$ e os menores por cv. Santa Rosa que apresentou em 2020 3,64 N e 2019 5,20 N (Tabela 4). Entre as safras apenas os porta-enxertos Barrier, Flordaguard, Tsukuba-2 e cv. Santa Rosa apresentaram diferenças, sendo os menores valores obtidos na safra 2018 para ambas cultivares, com exceção do cv. Santa Rosa que teve menor resultado em 2020. A firmeza dos frutos é medida por penetrômetro, que torna possível medir a resistência dos tecidos à compressão, e é considerado como principal atributo utilizado para estimar a vida útil de frutos, pois do ponto de vista prático, representa seu grau de resistência à movimentação, a danos e ao desenvolvimento de microrganismos (CREMASCO et al. 2016; GARCíA et al. 2018). ARGENTA et al. (2003) citam que a taxa de firmeza de $9 \mathrm{~N}$ em ameixas já é considerada própria para consumo, o que demonstra que os frutos avaliados estavam aptos ao consumo no momento da colheita. 
Tabela 4. Ratio e firmeza $(\mathrm{N})$ de frutos da cultivar Letícia produzidos com diferentes porta-enxertos e em plantas autoenraizadas na Região do Vale do Rio do Peixe, SC.

Table 4. Ratio and firmness $(N)$ of Letícia cultivar fruits produced with different rootstocks and on own-rooted plants, in the Rio do Peixe Valley region, SC.

\begin{tabular}{lllllll}
\hline \multicolumn{7}{c}{ Variáveis } \\
\hline \multirow{2}{*}{ Porta enxertos } & 2018 & 2019 & 2020 & 2018 & 2019 & 2020 \\
\cline { 2 - 8 } & $9,89 \mathrm{cA}$ & $7,80 \mathrm{bB}$ & $8,81 \mathrm{cB}$ & $6,72 \mathrm{bA}$ & $7,25 \mathrm{aA}$ & $7,86 \mathrm{aA}$ \\
Tsukuba -1 & $12,63 \mathrm{bA}$ & $7,74 \mathrm{bC}$ & $10,46 \mathrm{bB}$ & $6,07 \mathrm{cB}$ & $7,22 \mathrm{aA}$ & $7,48 \mathrm{aA}$ \\
Tsukuba - 2 & $10,23 \mathrm{cA}$ & $7,55 \mathrm{bB}$ & $9,44 \mathrm{cA}$ & $7,16 \mathrm{bA}$ & $7,10 \mathrm{aA}$ & $7,42 \mathrm{aA}$ \\
Tsukuba - 3 & $13,43 \mathrm{bA}$ & $9,11 \mathrm{aC}$ & $10,81 \mathrm{bB}$ & $5,22 \mathrm{cA}$ & $5,52 \mathrm{bA}$ & $6,04 \mathrm{bA}$ \\
Autoenraizada & $10,58 \mathrm{cA}$ & $8,46 \mathrm{aB}$ & $10,38 \mathrm{bA}$ & $8,18 \mathrm{aA}$ & $7,22 \mathrm{aA}$ & $7,19 \mathrm{aA}$ \\
G. x N9 & $12,10 \mathrm{bA}$ & $8,51 \mathrm{aB}$ & $9,11 \mathrm{cB}$ & $7,24 \mathrm{bA}$ & $7,35 \mathrm{aA}$ & $7,34 \mathrm{aA}$ \\
Cadaman & $10,24 \mathrm{cA}$ & $7,45 \mathrm{bB}$ & $10,17 \mathrm{bA}$ & $6,86 \mathrm{bA}$ & $7,75 \mathrm{aA}$ & $7,28 \mathrm{aA}$ \\
Capdebosq & $12,92 \mathrm{bA}$ & $9,26 \mathrm{aB}$ & $9,92 \mathrm{bB}$ & $5,97 \mathrm{cA}$ & $6,75 \mathrm{aA}$ & $6,57 \mathrm{aA}$ \\
Mariana & $14,72 \mathrm{aA}$ & $9,03 \mathrm{aB}$ & $10,06 \mathrm{bB}$ & $5,80 \mathrm{cB}$ & $6,05 \mathrm{bB}$ & $7,61 \mathrm{aA}$ \\
Barrier & $13,06 \mathrm{bA}$ & $8,83 \mathrm{aB}$ & $9,39 \mathrm{cB}$ & $6,45 \mathrm{cA}$ & $6,62 \mathrm{aA}$ & $7,36 \mathrm{aA}$ \\
México Fila 1 & $11,65 \mathrm{cA}$ & $8,46 \mathrm{aB}$ & $9,13 \mathrm{cB}$ & $6,28 \mathrm{cA}$ & $6,82 \mathrm{aA}$ & $7,27 \mathrm{aA}$ \\
Okinawa & $12,89 \mathrm{bA}$ & $8,24 \mathrm{bC}$ & $10,34 \mathrm{bB}$ & $6,43 \mathrm{cA}$ & $6,81 \mathrm{aA}$ & $5,90 \mathrm{bA}$ \\
Genovesa & $13,24 \mathrm{bA}$ & $7,86 \mathrm{bC}$ & $10,35 \mathrm{bB}$ & $5,79 \mathrm{cA}$ & $6,17 \mathrm{bA}$ & $6,21 \mathrm{bA}$ \\
Mirabolano & $13,64 \mathrm{bB}$ & $9,55 \mathrm{aC}$ & $19,46 \mathrm{aA}$ & $5,97 \mathrm{cA}$ & $5,20 \mathrm{bA}$ & $3,69 \mathrm{cB}$ \\
Santa Rosa & $12,86 \mathrm{bA}$ & $9,32 \mathrm{aB}$ & $9,70 \mathrm{cB}$ & $6,70 \mathrm{bA}$ & $6,17 \mathrm{bA}$ & $6,91 \mathrm{aA}$ \\
Ishtara & $14,92 \mathrm{aA}$ & $8,65 \mathrm{aB}$ & $9,16 \mathrm{cB}$ & $5,93 \mathrm{cB}$ & $6,60 \mathrm{aB}$ & $7,77 \mathrm{aA}$ \\
Flordaguard & $10,24 \mathrm{cA}$ & $7,45 \mathrm{bB}$ & $9,11 \mathrm{cA}$ & $6,86 \mathrm{bA}$ & $7,75 \mathrm{aA}$ & $8,00 \mathrm{aA}$ \\
Nemared & 9,21 & & & 11,00 & &
\end{tabular}

Mesma letra minúscula na coluna não apresenta diferença significativa para porta-enxerto dentro de safra. Mesma letra maiúscula na linha não apresenta diferença significativa para safra dentro de porta-enxerto.

Estas diferenças nos valores de firmeza dos diferentes estudos podem ser explicadas de acordo com CANDAN et al. (2011), que descrevem que mesmo os frutos colhidos no mesmo momento de maturação podem ser verificados diferentes valores de firmeza, devido a variação genética das cultivares. Além de uma variação genética, outro fator que pode explicar a baixa firmeza verificada nos frutos do presente estudo é uma maior produção de etileno, pois esse fito hormônio promove a atividade das enzimas responsáveis pelo amolecimento dos frutos (MAJUMDER \& MAZUMDAR 2002). ARGENTA et al. (2003) explicam que a cultivar Letícia apresenta alto padrão climatérico de respiração e produção de etileno, sendo estes fatores associados às rápidas mudanças de textura dos frutos, diminuindo assim a firmeza destes após a colheita.

A menor firmeza observada nos frutos obtidos das plantas enxertadas sobre cv. Santa Rosa, pode indicar maior maturação dos frutos em relação aos demais porta-enxertos, pois STEFFENS et al. (2011) explicam que existe uma relação direta entre a evolução do amadurecimento e a perda de firmeza da polpa, sendo o amadurecimento resultado de diversas reações bioquímicas. Uma baixa firmeza da polpa pode limitar o manuseio e o transporte após a colheita de frutos de caroço, tornando-os altamente sensíveis a danos mecânicos. Além disso, consumidores podem rejeitar frutos de caroço com baixa firmeza de polpa (ARGENTA et al. 2011). Cabe ressaltar que a cv. Santa Rosa foi utilizada como porta-enxerto por ser mais tolerante ao encharcamento de solo do que cultivares de pessegueiro, além de ser uma cultivar comum entre os produtores (MAYER \& UENO, 2019). Entretanto, ela apresenta alta suscetibilidade a doença vascular denominada escaldadura, que leva a desidratação dos tecidos e pode ocasionar distúrbios durante o período pós-colheita (KLEINA et al. 2018), pois o aumento resultante da respiração e a produção de etileno aceleram os processos de amadurecimento, redução no diâmetro do fruto, perda de peso, alterações de sabor e diminuição da firmeza da polpa (GIRONA et al. 2003; KLEINA et al. 2018). Esses fatores podem explicar as diferenças obtidas nos frutos que foram produzidos empregando a cv. Santa Rosa como portaenxerto.

As análises de coloração dos frutos luminosidade $\left({ }^{*} \mathrm{~L}\right)$, tonalidade $\left({ }^{\circ} \mathrm{HUE}\right)$ e intensidade de cor (Croma), foram realizadas nas safras 2019 e 2020 (Tabela 5). Para luminosidade, na safra 2019 não 
ocorreram diferenças significativas entre os porta-enxertos, e na safra 2020 apenas os porta-enxertos GxN9, Mirabolano 29C, Santa Rosa e nas plantas autoenraizadas diferiram dos demais devido aos menores resultados de luminosidade, os valores variaram de 31,99 a 37,92. Entre as safras, os porta-enxertos que apresentaram diferenças para luminosidade foram Capdesboscq, Genovesa, Mirabolano 29C e Santa Rosa, todos com valores inferiores em 2020. A luminosidade é dada pela coordenada de ${ }^{*} L$ que varia entre $0=$ preto a $100=$ branco, ou seja, valores altos de * $\mathrm{L}$ representam cores mais claras, e o oposto cores mais escura. Logo, os porta-enxertos GxN9, Mirabolano 29C, Santa Rosa e Letícia apresentaram frutos com epiderme mais escura durante a safra 2019 em relação aos demais porta-enxertos, o mesmo pode ser dito da safra 2020 para os porta-enxertos Capdesboscq, Genovesa, Mirabolano 29C e a cv. Santa Rosa em relação à safra 2019. A evolução da coloração do fruto do verde para o vermelho, ocorre a partir da degradação da clorofila e a biossíntese de antocianinas e carotenóides. A colheita de frutos com maturação mais elevada pode justificar a sua aparência, pois aumenta a pigmentação de cor vermelha da epiderme (STANGER et al. 2014).

Tabela 5. Luminosidade ( $\left.{ }^{*} \mathrm{~L}\right)$; Tonalidade de Cor ( $\left.{ }^{\circ} \mathrm{HUE}\right)$ e intensidade de Cor (Croma) de frutos da cultivar Letícia produzidos com diferentes porta-enxertos e em plantas autoenraizadas na Região do Vale do Rio do Peixe,SC.

Table 5. Luminosity ( $\left.{ }^{*} \mathrm{~L}\right)$; Color Tone ( $\left.{ }^{\circ} \mathrm{HUE}\right)$ and Color Intensity (Chroma) of Letícia cultivar fruits produced with different rootstocks and in own-rooted plants, in the Rio do Peixe Valley region, SC.

\begin{tabular}{|c|c|c|c|c|c|c|}
\hline \multicolumn{7}{|c|}{ Variáveis } \\
\hline \multirow{2}{*}{ Tratamentos } & \multicolumn{2}{|c|}{$\begin{array}{l}\text { Luminosidade } \\
\left({ }^{*} \mathrm{~L}\right)\end{array}$} & \multicolumn{2}{|c|}{$\begin{array}{l}\text { Tonalidade de cor } \\
\left({ }^{\circ} \mathrm{HUE}\right)\end{array}$} & \multicolumn{2}{|c|}{$\begin{array}{l}\text { Intensidade de Cor } \\
\text { (Croma) }\end{array}$} \\
\hline & 2019 & 2020 & 2019 & 2020 & 2019 & 2020 \\
\hline Tsukuba -1 & $37,80 \mathrm{aA}$ & $40,01 \mathrm{aA}$ & $25,94 \mathrm{aA}$ & $21,58 \mathrm{bA}$ & $30,24 a A$ & $25,60 \mathrm{aB}$ \\
\hline Tsukuba - 2 & $37,66 \mathrm{aA}$ & $39,21 a A$ & $25,32 \mathrm{aA}$ & $22,78 \mathrm{bA}$ & $29,57 a A$ & $25,60 \mathrm{aB}$ \\
\hline Tsukuba - 3 & $38,78 \mathrm{aA}$ & $37,16 a A$ & $27,19 \mathrm{aA}$ & $16,66 \mathrm{cB}$ & $29,15 \mathrm{aA}$ & $24,16 \mathrm{aB}$ \\
\hline Autoenraizada & $39,14 \mathrm{aA}$ & $35,83 \mathrm{bA}$ & $23,94 \mathrm{aA}$ & $15,11 \mathrm{cB}$ & $27,41 \mathrm{aA}$ & $24,44 \mathrm{aB}$ \\
\hline G. $\times$ N9 & $38,21 \mathrm{aA}$ & $36,53 \mathrm{bA}$ & $26,04 \mathrm{aA}$ & $15,38 \mathrm{cB}$ & $29,21 \mathrm{aA}$ & $23,65 \mathrm{aB}$ \\
\hline Cadaman & $40,90 \mathrm{aA}$ & $40,53 a A$ & $28,69 \mathrm{aA}$ & $24,38 \mathrm{bA}$ & $29,13 \mathrm{aA}$ & $26,56 \mathrm{aA}$ \\
\hline Capdebosq & $38,02 \mathrm{aA}$ & $34,09 \mathrm{aB}$ & $22,33 a A$ & $14,90 \mathrm{cB}$ & $26,74 \mathrm{aA}$ & $25,63 a A$ \\
\hline Mariana & $38,09 \mathrm{aA}$ & $37,65 a A$ & $22,80 \mathrm{aA}$ & $18,26 \mathrm{cA}$ & $28,68 \mathrm{aA}$ & $25,04 \mathrm{aB}$ \\
\hline Barrier & $39,58 \mathrm{aA}$ & $37,88 \mathrm{aA}$ & $29,34 a A$ & $18,06 \mathrm{cB}$ & $29,99 \mathrm{aA}$ & $24,50 \mathrm{aB}$ \\
\hline México Fila 1 & $37,40 \mathrm{aA}$ & $39,08 \mathrm{aA}$ & $22,61 \mathrm{aA}$ & $17,17 \mathrm{cA}$ & $28,36 a A$ & $24,73 a B$ \\
\hline Okinawa & $38,71 \mathrm{aA}$ & $40,68 \mathrm{aA}$ & $26,02 \mathrm{aA}$ & $22,42 b A$ & $28,55 \mathrm{aA}$ & $24,77 \mathrm{aB}$ \\
\hline Genovesa & $42,25 \mathrm{aA}$ & $37,92 \mathrm{aB}$ & $24,83 a A$ & $16,66 \mathrm{cB}$ & $14,51 \mathrm{bA}$ & $22,25 \mathrm{aB}$ \\
\hline Mirabolano & $41,34 \mathrm{aA}$ & $36,49 b B$ & $27,32 \mathrm{aA}$ & $18,42 \mathrm{cB}$ & $32,02 \mathrm{aA}$ & $24,94 \mathrm{aB}$ \\
\hline Santa Rosa & $40,03 a A$ & $31,99 \mathrm{bB}$ & $23,17 \mathrm{aB}$ & $357,00 \mathrm{aA}$ & $27,60 \mathrm{aA}$ & $16,36 \mathrm{bB}$ \\
\hline Ishtara & $39,58 a A$ & $38,25 a A$ & $25,76 a A$ & $16,38 \mathrm{cB}$ & $29,88 a A$ & $24,75 \mathrm{aB}$ \\
\hline Flordaguard & $40,47 a A$ & $40,50 \mathrm{aA}$ & $28,61 \mathrm{aA}$ & $23,15 b A$ & $29,91 \mathrm{aA}$ & $26,03 \mathrm{aB}$ \\
\hline Nemared & $37,69 \mathrm{aA}$ & $37,99 \mathrm{aA}$ & $24,88 \mathrm{aA}$ & $28,84 \mathrm{bA}$ & $29,04 a \mathrm{~A}$ & $26,81 \mathrm{aB}$ \\
\hline CV (\%) & & 7,24 & & 14,47 & & 7,8 \\
\hline
\end{tabular}

Mesma letra minúscula na coluna não apresenta diferença significativa para porta-enxerto dentro de safra. Mesma letra maiúscula na linha não apresenta diferença significativa para safra dentro de porta-enxerto. NS não apresenta diferença significativa.

Assim como a luminosidade, a tonalidade da cor ( $\left.{ }^{\circ} \mathrm{HUE}\right)$ não apresentou diferenças significativas entre os porta-enxertos na safra 2019 (Tabela 5). As plantas autoenraizadas, assim como, aquelas enxertadas sobre Tsukuba-3, GxN9, Capdeboscq, Barrier, Genovesa, Mirabolano 29C e Ishtara diferiram estatisticamente entre as safras, apresentando valores mais elevados em 2019. A Santa Rosa também diferiu entre safras, porém com comportamento oposto aos porta-enxertos, com menor valor de ${ }^{\circ} \mathrm{HUE}$ em 2019. Cabe ressaltar que os valores de ${ }^{\circ} \mathrm{HUE}$ oscilaram de 15,11 para Letícia em 2020 a 29,34 para Barrier em 2019, com exceção do Santa Rosa em 2020 que apresentou um valor de 357. O Ângulo ${ }^{\circ}$ Hue é considerado $o$ atributo qualitativo de cor com as cores que definidas tradicionalmente como avermelhada, esverdeada, entre outras. Graficamente consideramos o ângulo de $0^{\circ}$ como a cor vermelha, o ângulo de 


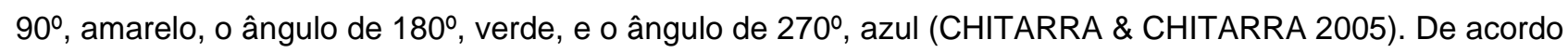
com as fixas de valores observados nos frutos avaliados podemos definir que o porta-enxerto Santa Rosa em 2020 gerou frutos na faixa de cor da púrpura avermelhada, enquanto os demais se mantiveram na faixa do vermelho púrpura em 2019 e 2020.

A intensidade de cor foi maior para os frutos colhidos na safra 2019, com exceção de Cadaman, Capdeboscq e Nemared que não apresentaram diferenças entre as safras (Tabela 5). Entre os portaenxertos em 2019 o Genovesa diferiu dos demais devido ao menor valor (14,51), em 2020 o menor valor foi do Santa Rosa $(16,36)$, diferindo do restante. Os demais porta-enxertos apresentaram valores que variaram de 26,74 para Capdebosc a 32,02 para Mirabolano em 2019 e 22,25 a 26,81 para Genovesa e Nemared, respectivamente, em 2020. STANGER et al. (2014) explicam que a coloração dos frutos muda de acordo com o avanço da maturação e a intensidade varia conforme as condições climáticas locais.

PALOU \& CRISOSTO (2003) e WANG et al. (2016) explicam que as variações na coloração da epiderme dos frutos ocorrem principalmente devido ao contato do etileno produzido pelo processo de maturação dos frutos após serem colhidos, o que leva a ação de enzimas que degradam a clorofila e realizam a síntese de carotenoides (UENOJO et al. 2007). A colheita precoce de frutos pode prejudicar a sua aparência, pois reduz a pigmentação de cor vermelha da epiderme (CASQUERO \& GUERRA 2009). STANGER et al. (2014) verificaram uma menor evolução da cor dos frutos colhidos no ponto M1 (0-25\% da superfície do fruto pigmentada de vermelho), justificando que este fato pode estar relacionado com a redução do processo de degradação da clorofila e/ou a sua incapacidade de sintetizar antocianinas.

\section{CONCLUSÃO}

Com exceção dos porta-enxertos Rigitano, Clone 15, Nemared e 1-67-52-4 que apresentam incompatibilidade, todos os materiais testados se mostraram opções viáveis de porta-enxerto para a cv Letícia do ponto de vista de qualidade dos frutos

Plantas autoenraizadas de 'Letícia' produzem frutos com características físico-químicas semelhantes aos produzidos em plantas enxertadas nos porta-enxertos testados, tornando-se uma opção tecnicamente interessante de cultivo sem o uso de porta-enxertos.

\section{REFERÊNCIAS}

ANZANELLO R \& MENIN RP. 2018. Cultivares potenciais de pessegueiro, ameixeira e quivizeiro para a região da Serra Gaúcha. Pesquisa Agropecuária Gaúcha 24: 1-11.

ARGENTA LC et al. 2003. Ripening and quality of "Laetitia" plums following harvest and cold storage as affected by inhibition of ethylene action. Pesquisa Agropecuária Brasileira 38: 1139-1148.

ARGENTA LC et al. 2011. Controle do escurecimento interno de ameixas durante o armazenamento pelo manejo do ponto de colheita e do etileno. Revista Brasileira de Fruticultura 33: 376-385.

BAUCHROWITZ IM. 2018. Pós colheita de frutos de ameixa armazenados em temperatura ambiente e a $1^{\circ} \mathrm{C}$ tratados com etefom. Dissertação (Mestrado em Agronomia). Ponta Grossa: UEPG. 89p.

BAUCHROWITZ IM et al. 2019a. Comportamento fenológico e qualidade dos frutos de genótipos de ameixa japonesa no município de Ponta Grossa-PR. Revista Terra \& Cultura: Cadernos de Ensino e Pesquisa 35: 20-31.

BAUCHROWITZ IM. et al. 2019b. Japanese plum performance assessment (Prunus salicina Lind.) cultivar byron in the municipality of Ponta Grossa-PR. Applied Research \& Agrotechnology 12: 111-117.

CANDAN AP et al. 2011. La calidad postcosecha y los daños por frío en ciruelas: Beneficios del 1-metilciclopropeno. Spanish Journal of Agricultural Research 9: 554-564.

CASQUERO PA \& GUERRA M. 2009. Harvest parameters to optimise storage life of European plum "Oullins Gage". International Journal of Food Science and Technology 44: 2049-2054.

CHAGAS PC. 2008. Cultivares de ameixas de baixa exigência em frio para regiões subtropicais do Estado de São Paulo. Dissertação (Mestrado em Agronomia). Piracicaba: USP. 123p.

CHITARRA MIF \& CHITARRA AB. 2005. Pós-colheita de frutos e hortaliças: fisiologia e manuseio. 2.ed. Lavras: UFLA. p.394.

CREMASCO JPG et al. 2016. Qualidade pós-colheita de oito variedades de pêssego. Comunicata Scientiae 7: 334-342.

CRISOSTO $\mathrm{CH}$ et al. 2007. Segregation of plum and pluot cultivars according to their organoleptic characteristics.

Postharvest Biology and Technology 44: 271-276.

CUQUEL FL et al. 2011. Nitrogen and potassium fertilization affecting the plum postharvest quality. Revista Brasileira de Fruticultura 33: 328-336.

DíAZ-MULA HM et al. 2009. Changes in hydrophilic and lipophilic antioxidant activity and related bioactive compounds during postharvest storage of yellow and purple plum cultivars. Postharvest Biology and Technology 51: 354-363.

DONADIO LC et al. 2019. Dwarfing-canopy and rootstock cultivars for fruit trees. Revista Brasileira de Fruticultura 41: 112.

EIDAM T et al. 2010. Ameixeira no Brasil. Revista Brasileira de Fruticultura 34: 656. 
FACHINELLO JC et al. 2000. Resistência de porta-enxertos para pessegueiro e ameixeira aos nematóides causadores de galhas (Meloidogyne spp.). Ciência Rural 30: 69-72.

FIORAVANÇO J et al. 2015. Avaliação Agronômica da Ameixeira "Letícia" em Vacaria. RS. Bento Gonçalves: EMBRAPA. 8p. (Circular Técnica 122).

GARCÍA EQ et al. 2018. Quality of peach fruits jarillo cv. (prunus persica L.) in pamplona, Colombia. Revista Brasileira de Fruticultura 40: 1-14.

GIRONA J et al. 2003. Peach tree response to single and combined regulated deficit irrigation regimes under shallow soils. Journal of the American Society for Horticultural Science 128: 432-440.

GUERRA LJ et al. 1992.Influência do alagamento na mortalidade do pessegueiro e da ameixeira. Pesquisa Agropecuária Brasileira 27: 499-508.

JIMENES IM et al. 2020. Initial performance of own-rooted and budded "Sunraycer" nectarine plants. Pesquisa Agropecuária Brasileira 55: 1-6.

KLEINA HT et al. 2018. Postharvest quality of plums in response to the occurrence of leaf scald disease. Postharvest Biology and Technology 143: 102-111.

KLEINA F. 2008. Porta-enxertos para a cultura do pêssegueiro do terceiro milênio. Revista Brasileira de Fruticultura 30: 274-284.

MACHADO WM et al. 2013. Efeito do processamento e armazenamento em compostos fenólicos presentes em frutas e hortaliças. Publicatio UEPG: Ciências Exatas e da Terra, Agrárias e Engenharias 19: 1-17.

MAJUMDER K \&MAZUMDAR BC 2002. Changes of pectic substances in developing fruits of cape-gooseberry (Physalis peruviana L.) in relation to the enzyme activity and evolution of ethylene. Scientia Horticulturae 96: 91-101.

MAYER et al. 2018. Leaf nutrient content on seven plum cultivars with grafted by budding or own-rooted trees. Revista Brasileira de Fruticultura 40: 1-12.

MAYER NA et al. 2017. Advances in peachu, nectarine and plum propagation. Revista Brasileira de Fruticultura 39: 121.

MAYER NA \& PEREIRA FM 2006. Vigor de clones de umezeiro e pessegueiro "Okinawa" propagados por estacas herbáceas. Pesquisa Agropecuária Brasileira 41: 883-887.

MAYER NA et al. 2008. Caracterização morfológica de três genótipos de umezeiro selecionados como porta-enxertos para pessegueiro. Revista Brasileira de Fruticultura 30: 716-722.

MAYER NA et al. 2005. Resistência de clones de umezeiro e cultivares de pessegueiro a Meloidogyne incognita (nemata: Heteroderidae). Revista Brasileira de Fruticultura 27: 335-337.

MINAS IS et al. 2013. Postharvest handling of plums (Prunus salicina Lindl.) at $10^{\circ} \mathrm{C}$ to save energy and preserve fruit quality using an innovative application system of 1-MCP. Postharvest Biology and Technology. 76. 1-9.

MORAIS KDB de et al. 2017. Avaliação física e química de frutos de cultivares de pessegueiro. Revista Engenharia na Agricultura 25: 157-163.

OLDONI CM et al. 2019. Peroxidase activity and initial growth of 'Barbosa' peach on clonal rootstocks. Revista Brasileira de Fruticultura 41: 1-10.

OLIVEIRA JAA et al. 2020. Initial development of peach rootstock genotypes propagated by herbaceous cuttings. Revista Brasileira de Fruticultura 42: 1-5.

PALOU L \& CRISOSTO CH 2003. The influence of exogenous ethylene application during cold storage on stone fruit quality and brown rot development. Acta Horticulturae 628: 269-276.

PEREIRA FM et al. 2007. Rigitano: nova cultivar de umezeiro para porta-enxerto de pessegueiro. Revista Brasileira de Fruticultura 29: 172-175.

PIO R et al. Selection of plum cultivars for subtropical regions. Ciência Rural 48: 1-7.

QUEIROZ HT 2014.Caracterização de Genótipos de Pessegueiros e ameixeiras na depressão central do Estado do Rio Grande do Sul. Dissertação (Mestrado em Agronomia). Porto Alegre: UFRGS. 82p.

SAARELA $M$ et al. 2011. Improving the storage stability of Bifidobacterium breve in low pH fruit juice. International Journal of Food Microbiology 149: 106-110.

SANTANA A et al. 2020. Genetic diversity of the genus Prunus based on per se evaluation of peach clonal rootstocks. Revista de Ciências Agrárias 63: 1-7.

SBCS/CQFS. 2004. Manual de adubação e de calagem para os Estados do Rio Grande do Sul e de Santa Catarina.10.ed. Porto Alegre: Sociedade Brasileira de Ciência do Solo/Núcleo Regional Sul. 400p.

SCHMITZ J et al. 2012. Vigor e produtividade do pessegueiro 'Chimarrita' sobre diferentes porta-enxertos. Revista Brasileira de Agrociência 18: 1-10.

SHARMA S \& SHARMA RR 2016. Impact of staggered treatments of novel molecules and ethylene absorbents on postharvest fruit physiology and enzyme activity of "Santa Rosa" plums. Scientia Horticulturae 198: 242-248.

STANGER MC et al. 2014. Qualidade pós-colheita de ameixas "Camila" e "Laetitia" colhidas em diferentes estádios de maturação. Revista Caatinga 27: 214-221.

STEFFENS CA et al. 2011. Maturação e qualidade pós-colheita de ameixas "Laetitia" com a aplicação pré-colheita de AVG e GA3. Revista Brasileira de Fruticultura 33: 021-031.

SZYMAJDA M et al. 2019. A potential of new peach (Prunus persica L.) seed tree genotypes for the production of generative rootstocks. Scientia Horticulturae 256: 1-6.

VIEIRA EA et al. 2005. Genetic mapping of Japanese plum. Crop Breeding and Applied Biotechnology 5: 29-37.

VIEITES RL et al. 2016. Qualidade Pós-Colheita de Clones de Umê Cultivados em Jundiaí-SP. Nativa 4: $386-391$.

Rev. Ciênc. Agrovet., Lages, SC, Brasil (ISSN 2238-1171) 
WANG $\mathrm{J}$ et al. 2016. Patterns of flesh reddening, translucency, ethylene production and storability of 'Friar' plum fruit harvested at three maturity stages as affected by the storage temperature. Postharvest Biology and Technology 121 : 9-18.

YANG Z et al. 2012. Combined salicylic acid and ultrasound treatments for reducing the chilling injury on peach fruit. Journal of Agricultural and Food Chemistry 60: 1209-1212. 